\title{
Calcium-Activated Potassium Conductances Contribute to Action Potential Repolarization at the Soma But Not the Dendrites of Hippocampal CA1 Pyramidal Neurons
}

\author{
Nicholas P. Poolos and Daniel Johnston \\ Division of Neuroscience, Baylor College of Medicine, Houston, Texas 77030
}

\begin{abstract}
Evidence is accumulating that voltage-gated channels are distributed nonuniformly throughout neurons and that this nonuniformity underlies regional differences in excitability within the single neuron. Previous reports have shown that $\mathrm{Ca}^{2+}, \mathrm{Na}^{+}$, A-type $\mathrm{K}^{+}$, and hyperpolarization-activated, mixed cation conductances have varying distributions in hippocampal CA1 pyramidal neurons, with significantly different densities in the apical dendrites compared with the soma. Another important channel mediates the large-conductance $\mathrm{Ca}^{2+}$-activated $\mathrm{K}^{+}$ current $\left(I_{C}\right)$, which is responsible in part for repolarization of the action potential (AP) and generation of the afterhyperpolarization that follows the AP recorded at the soma. We have investigated whether this current is activated by APs retrogradely propagating in the dendrites of hippocampal pyramidal neurons using whole-cell dendritic patch-clamp recording techniques.
\end{abstract}

Recent advances in recording techniques have shown that voltage-gated channels are distributed nonuniformly throughout the hippocampal pyramidal neuron; these include $\mathrm{Ca}^{2+}$ channels (Elliott et al., 1995; Magee and Johnston, 1995a) and $\mathrm{Na}^{+}$channels, which have a relatively constant density throughout the cell but differ in their inactivation properties between the soma and dendrites (Colbert et al., 1997; Mickus et al., 1999). The distributions of the transient A-type $\mathrm{K}^{+}$current and the hyperpolarization-activated cation current $\left(I_{h}\right)$ both show dramatic nonuniformity, increasing in density with distance in the apical dendrites (Hoffman et al., 1997; Magee, 1998). The differential distribution of these voltage-gated channels between soma and dendrites yields significant differences in excitability between these two regions. For example, the increased A-current density causes the dendrites to be relatively less excitable than the soma, such that with increasing distance from the soma, dendritic action potential (AP) amplitude progressively decreases, and the threshold for AP initiation increases (Hoffman et al., 1997).

Less is known about the distribution of $\mathrm{Ca}^{2+}$-activated $\mathrm{K}^{+}$ channels in neurons, in particular the current generated by the large-conductance $\mathrm{Ca}^{2+}$-activated $\mathrm{K}^{+}$channel or BK channel. This current (here abbreviated $I_{C}$ ) has been studied with somatic recordings at the hippocampal pyramidal neuron, as well as in

Received March 4, 1999; revised April 8, 1999; accepted April 12, 1999.

This work was supported by the National Institute of Neurological Disorders and Stroke (NINDS) Grant NS01981 to N.P.P., a grant from the Epilepsy Foundation of America to N.P.P., the National Institute of Mental Health Grant MH48432 to D.J., NINDS Grant NS37444 to D.J., and grants from the Human Frontiers Science Project and the Hankamer Foundation to D.J.

Correspondence should be addressed to Dr. Daniel Johnston, Division of Neuroscience S-603, Baylor College of Medicine, Houston, TX 77030.

Copyright (C) 1999 Society for Neuroscience $0270-6474 / 99 / 195205-08 \$ 05.00 / 0$
We found no $I_{C}$ activation by back-propagating APs in distal dendritic recordings. Dendritic APs activated $I_{C}$ only in the proximal dendrites, and this activation decayed within the first $100-150 \mu \mathrm{m}$ of distance from the soma. The decay of $I_{C}$ in the proximal dendrites occurred despite AP amplitude, plus presumably AP-induced $\mathrm{Ca}^{2+}$ influx, that was comparable with that at the soma. Thus we conclude that $I_{C}$ activation by action potentials is nonuniform in the hippocampal pyramidal neuron, which may represent a further example of regional differences in neuronal excitability that are determined by the nonuniform distribution of voltage-gated channels in dendrites.

Key words: dendrites; hippocampus; calcium-activated potassium conductances; back-propagation; action potentials; patch clamp; calcium many other neurons (for review, see Sah, 1996; Vergara et al., 1998). The BK channels that underlie $I_{C}$ generate a high singlechannel conductance for $\mathrm{K}^{+}$, are both voltage- and $\mathrm{Ca}^{2+}$ sensitive, rapidly open with $\left[\mathrm{Ca}^{2+}\right]_{\mathrm{i}}$ rises in the range of $1-10 \mu \mathrm{M}$, and are blocked by charybdotoxin (CTX) and submillimolar concentrations of tetraethylammonium (TEA) (Barrett et al., 1982; Blatz and Magleby, 1984). $I_{C}$ activation occurs with $\mathrm{Ca}^{2+}$ influx induced by APs and contributes to the rapid repolarization of the AP and subsequent fast afterhyperpolarization (AHP) (Lancaster and Adams, 1986; Storm, 1987). This current is distinct from that generated by small-conductance $\mathrm{Ca}^{2+}$-activated $\mathrm{K}^{+}$channels (SK), which are $\mathrm{Ca}^{2+}$ - but not voltage-sensitive, activate slowly in response to submicromolar rises in $\left[\mathrm{Ca}^{2+}\right]_{i}$, show varying sensitivity to apamin, and generate the slow AHP after a train of APs (Lancaster and Zucker, 1994; Sah, 1996; Vergara et al., 1998).

Although the role of $I_{C}$ in repolarizing the AP is well documented for APs initiated at the soma of hippocampal pyramidal neurons, it is unknown whether this current is present in the dendrites and whether it contributes to the repolarization of the dendritic AP. Since the initial descriptions of retrograde AP propagation in the dendrites (or "back-propagation"), it has been appreciated that dendritic APs differ from somatic APs in that the amplitude of dendritic APs is variable, diminishing with distance from the soma, they lack an afterhyperpolarizing phase, and their repolarization is slower (Andreasen and Lambert, 1995; Spruston et al., 1995; Colbert et al., 1997). We therefore questioned whether $I_{C}$ is activated by APs back-propagating in the dendrites as it is by APs at the soma. Because we were interested in assessing this functional role of $I_{C}$, we used whole-cell patchclamp recordings in the dendrites of hippocampal CA1 pyramidal 


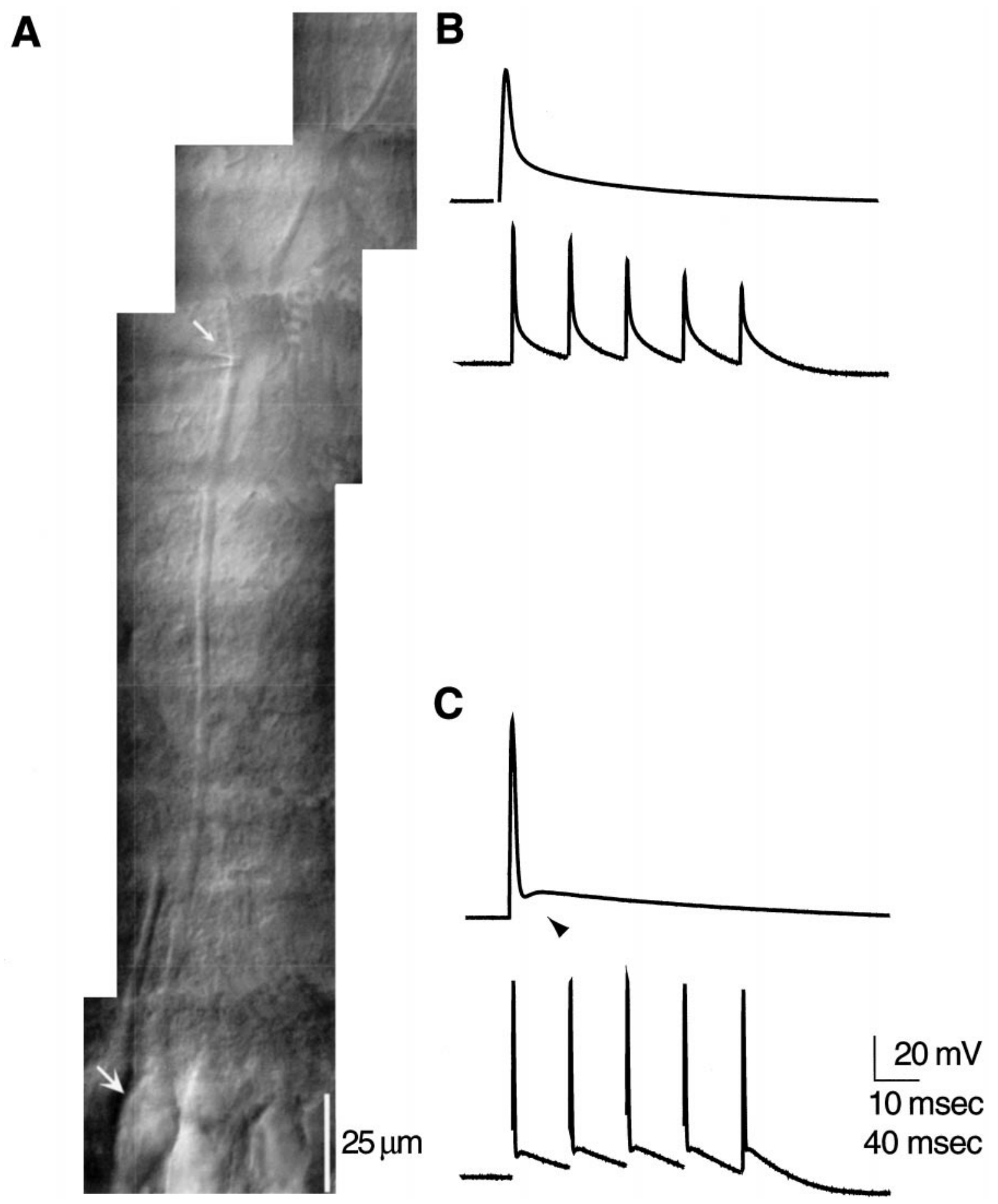

Figure 1. Back-propagating APs recorded in the apical dendrites lack a fast AHP. A, Hippocampal CA1 pyramidal neurons were visualized using IR-DIC optics. The large arrow points to cell soma; the small arrow points to the apical dendrite $\sim 150 \mu \mathrm{m}$ from the soma, where a patch pipette can be faintly seen. B, Top, Back-propagating dendritic action potentials (trace shown) differ from somatic action potentials in their smaller amplitude, slower repolarization, and lack of a fast AHP. Bottom, When APs were repetitively stimulated, dendritic APs decremented in amplitude over the course of the train. $C$, Top, Somatic action potentials showed much faster repolarization and a fast AHP (arrowhead) after the AP. Bottom, When repetitively stimulated, somatic APs had a nearly constant amplitude. Synaptic blocks were omitted in this experiment.

neurons to measure $I_{C}$ activation by back-propagating action potentials.

\section{MATERIALS AND METHODS}

Hippocampal slices were prepared from 6- to 10-week-old male Sprague Dawley rats. Animals were anesthetized with a lethal dose of a combination of ketamine, xylazine, and acepromazine injected intraperitoneally. After being deeply anesthetized, the animal was perfused intracar- dially with ice-cold modified artificial CSF containing (in $\mathrm{mM}$ ): 110 choline chloride, $2.5 \mathrm{KCl}, 1.25 \mathrm{NaH}_{2} \mathrm{PO} 4,0.5 \mathrm{CaCl}_{2}, 7 \mathrm{MgCl}_{2}, 7 \mathrm{dex}-$ trose, 3 pyruvic acid, and 1.3 ascorbic acid. The brain was then removed, and $400-\mu \mathrm{m}$-thick slices were prepared using a vibratome (Lancer). Hippocampal slices were stored until use in a holding chamber containing external recording solution at room temperature.

Recordings from hippocampal pyramidal neurons were obtained from slices maintained in a submerged chamber at $30-32^{\circ} \mathrm{C}$. The external 


\section{A soma}

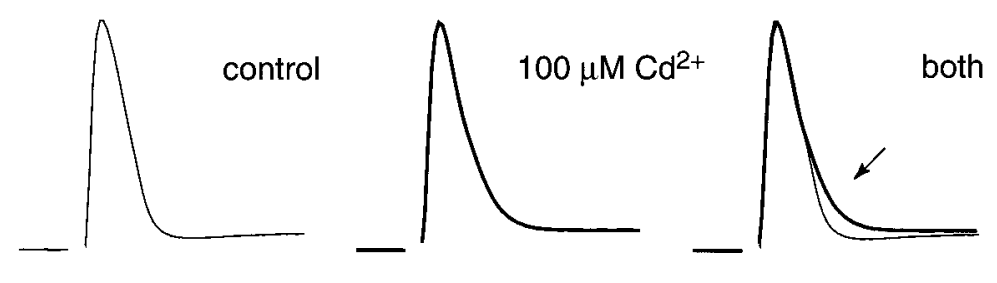

$160 \mu \mathrm{m}$ dendrite

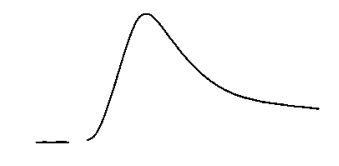

B soma

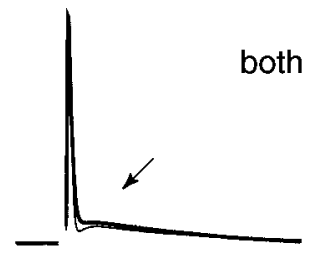

$160 \mu \mathrm{m}$ dendrite

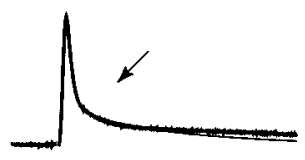

$20 \mathrm{mV}$ $10 \mathrm{msec}$

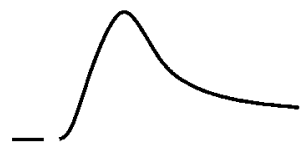

C
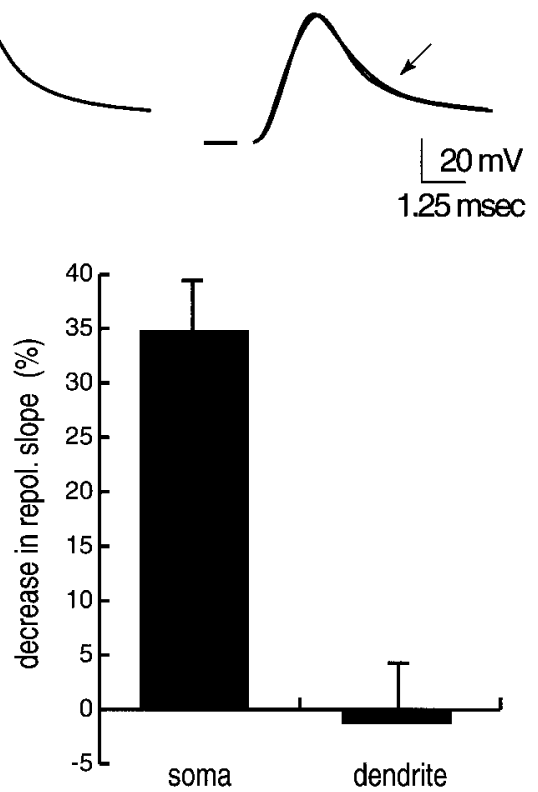

Figure 2. Repolarization of action potentials in the distal dendrites is not affected by $\mathrm{Ca}^{2+}$ channel blockade. $A$, Top, Action potentials recorded at the soma are shown under control and $100 \mu \mathrm{M} \mathrm{Cd}{ }^{2+}$ conditions. Right, Superimposed APs show that $\mathrm{Ca}^{2+}$ channel blockade significantly slowed AP repolarization and blocked the fast AHP (arrow). Bottom, Repolarization of dendritic APs was not significantly affected by $\mathrm{Ca}^{2+}$ channel blockade. $B$, The same responses presented in $A$ (right) are shown at a longer time scale to show block of the fast AHP (arrow) at the soma by $100 \mu \mathrm{M}$ $\mathrm{Cd}^{2+} . C$, Summary of data shows the average decrease in AP repolarization (repol.) slope between control and $\mathrm{Ca}^{2+}$ channel blockade conditions (grouped data from 100-200 $\mu \mathrm{M} \mathrm{Cd}^{2+}$ and from $0 \mathrm{Ca}^{2+}$ and $6 \mathrm{mM} \mathrm{Mg}^{2+}$ solutions; $n=$ 8 for soma, $n=9$ for dendrite). recording solution contained (in $\mathrm{mm}$ ): $125 \mathrm{NaCl}, 2.5 \mathrm{KCl}, 1.25 \mathrm{NaH}_{2} \mathrm{PO}_{4}$, $2 \mathrm{CaCl}_{2}, 2 \mathrm{MgCl}_{2}$, and 10 dextrose, bubbled continuously with $95 \%$ $\mathrm{O}_{2} / 5 \% \mathrm{CO}_{2} ; \mathrm{pH}$ was adjusted to 7.4 with $\mathrm{NaOH}$. The internal recording pipette solution contained (in mM): $120 \mathrm{KMeSO}_{4}, 20 \mathrm{KCl}, 10 \mathrm{HEPES}, 2$ $\mathrm{MgCl}_{2}, 4 \mathrm{Na}_{2}$-ATP, 0.3 Tris; $\mathrm{pH}$ was adjusted to 7.3 with $\mathrm{KOH}$.

Whole-cell patch-clamp recordings were made from hippocampal CA1 pyramidal neuron somata and dendrites that were visualized using infrared differential interference contrast microscopy (IR-DIC; Zeiss Axioskop). Pipettes were fabricated with a Flaming-Brown puller (Sutter Instruments) using borosilicate glass (Fisher Scientific, Houston, TX) and had DC resistances of $\sim 10 \mathrm{M} \Omega$. Whole-cell recordings were obtained with a bridge-mode amplifier (Dagan BVC-700), digitized at 10 $\mathrm{kHz}$ (IOTech), and stored with custom data acquisition software. Wholecell series resistance was $10-25 \mathrm{M} \Omega$ for somatic recordings and 15-50 $\mathrm{M} \Omega$ for dendritic recordings. Recordings without stable series resistance were discarded. Antidromic action potentials were elicited by constantcurrent pulses (WPI) delivered by a tungsten electrode (AM Systems) placed in the alveus. Recordings are shown with stimulus artifacts truncated for clarity. In some cases, action potentials were elicited by brief depolarizing current pulses delivered through the somatic recording pipette. All drugs were bath-applied. CNQX (10 $\mu \mathrm{M}$; Research Biochemicals, Natick, MA) and bicuculline methiodide ( $25 \mu \mathrm{M}$; Sigma, St. Louis, MO) were routinely added to the external solution to block postsynaptic potentials. Charybdotoxin (Alomone Laboratories) was prepared and applied in a solution of $0.01 \%$ bovine serum albumin (Sigma) to prevent nonspecific binding of the toxin to tubing. Application of bovine serum albumin-containing solution alone had no apparent effect on action potential firing (data not shown).

Changes in somatic action potential repolarization were quantified by measuring the linear slope of repolarization (volts per second) at two time points on the repolarizing phase of the AP: one at $80 \%$ of peak AP amplitude (measured peak to baseline) and the other at $20 \%$ of peak amplitude. This method allowed measurement of the rate of AP repolarization over a reasonably linear segment of the waveform, as was used by Storm (1987). Dendritic APs were measured similarly except that the second point was taken at $30 \%$ of peak amplitude; because dendritic APs have a slower, more exponential late phase in repolarization, measuring between the 80 and $30 \%$ points captured a more linear segment of repolarization. In experiments (see Fig. 6) in which the change in repolarization was compared in the soma and at varying distances along the dendrites, the repolarization slope in both soma and dendrites was measured at the $80-30 \%$ points for consistency. Changes in repolarization are shown as the percent decrease in repolarization; that is, slower repolarization is represented by a positive number. Data are reported as mean \pm SEM.

\section{RESULTS}

\section{Dendritic action potentials lack a fast afterhyperpolarization}

Whole-cell patch-clamp recordings were obtained from visualized CA1 hippocampal pyramidal neurons either at the soma or in the apical dendrites at distances up to $200 \mu \mathrm{m}$ from the soma (Fig. $1 A$ ). Antidromic activation of single APs or trains of APs by alvear stimulation resulted in an AP that was recorded at the soma [but presumably initiated at the axon initial segment or first node of Ranvier (see Colbert and Johnston, 1996)] and then propagated retrogradely (back-propagated) into the apical dendrites (Spruston et al., 1995). Action potentials recorded in the dendrites differed from their somatic counterparts in several ways (Fig. 1B,C). First, the amplitude of single dendritic APs declined with distance from the soma beyond $\sim 70 \mu \mathrm{m}$, such that at the mean distal dendritic recording location $(174 \pm 5 \mu \mathrm{m} ; n=9)$, their amplitude was $57.5 \pm 2.7 \mathrm{mV}$, compared with $98.4 \pm 1.1 \mathrm{mV}$ $(n=8)$ at the soma. Second, during a train of APs, the amplitude of dendritic APs declined continually during the course of the 


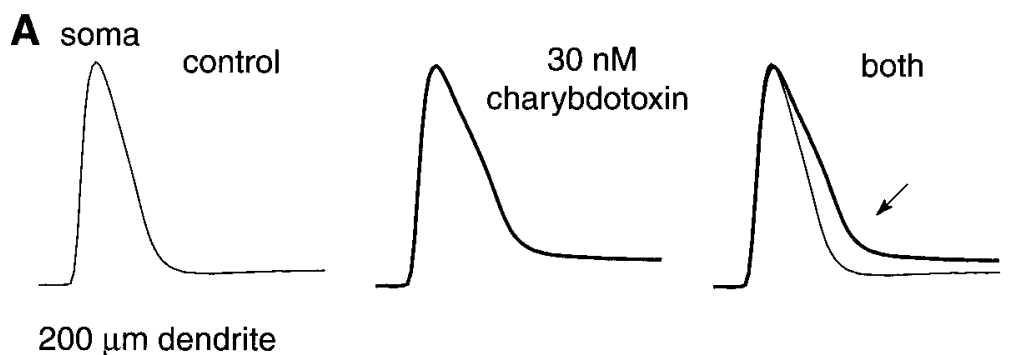

Figure 3. Blockade of $\mathrm{Ca}^{2+}$-activated $\mathrm{K}^{+}$currents does not affect repolarization of dendritic action potentials. $A$, Top, Action potentials recorded at the soma showed slowing of repolarization and blockade of the fast AHP (arrow) by CTX, an inhibitor of large-conductance $\mathrm{Ca}^{2+}$-activated $\mathrm{K}^{+}$ conductances. Bottom, Repolarization of dendritic action potentials was not affected by CTX. $B$, TEA, in low concentrations, blocks $I_{C}$ to the exclusion of most other $\mathrm{K}^{+}$ channels. Application of TEA (1 mM) slowed AP repolarization at the soma (top), while having a minimal effect on dendritic APs (bottom).
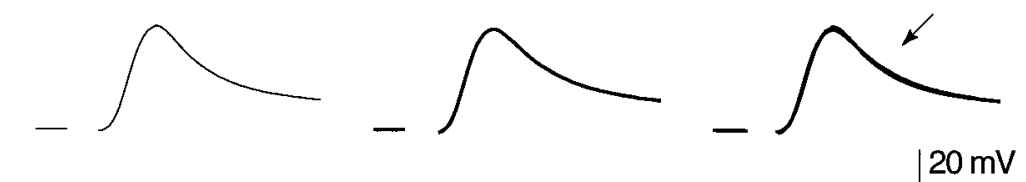

B soma
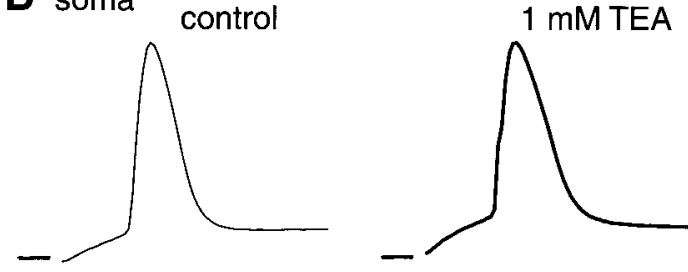
1 mM TEA $1.25 \mathrm{msec}$

$180 \mu \mathrm{m}$ dendrite
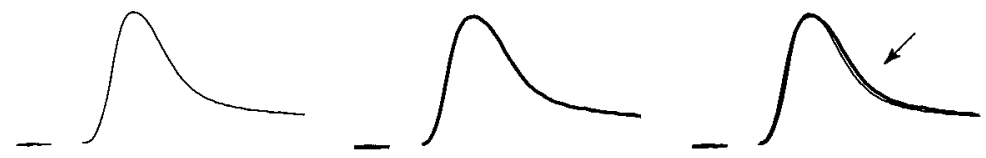

train, whereas the amplitude of somatic APs remained constant. Finally, single dendritic APs had a significantly slower repolarization than did somatic APs and lacked the fast afterhyperpolarizing phase present in somatic APs. These observations were consistent with previous reports on dendritic AP characteristics (Andreasen and Lambert, 1995; Colbert et al., 1997).

\section{Repolarization of action potentials in distal dendrites is not affected by $\mathrm{Ca}^{2+}$ channel blockade}

Although dendritic action potentials clearly lacked a fast AHP, it was not clear whether $\mathrm{Ca}^{2+}$-activated $\mathrm{K}^{+}$currents contributed to dendritic AP repolarization without producing an overt AHP. To study this question, we elicited single antidromic APs in control

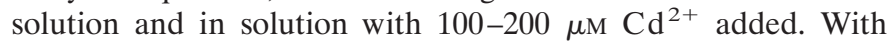
action potentials recorded at the soma, the blockade of $\mathrm{Ca}^{2+}$ channels with $\mathrm{Cd}^{2+}$ caused slowing of repolarization and blockade of the fast AHP (Fig. 2A,B). Similar results were also obtained with solutions containing $0 \mathrm{Ca}^{2+}$ and $6 \mathrm{mM} \mathrm{Mg}^{2+}$ (data not shown). When this effect was quantified by measuring the decrease in the rate of repolarization (as described in Materials and Methods), the blockade of $\mathrm{Ca}^{2+}$ channels caused a $34.7 \pm$ $4.7 \%(n=8)$ decrease in repolarization rate. This result was consistent with the previous work of Storm (1987), who found that a decrease of $38 \pm 6.3 \%$ in repolarization rate appeared to represent the effect of maximal blockade of $I_{C}$ on AP repolarization at the soma.

In contrast, the repolarization of dendritic action potentials obtained $>150 \mu \mathrm{m}$ from the soma was not affected by the blockade of $\mathrm{Ca}^{2+}$ channels with $\mathrm{Cd}^{2+}$ (Fig. $2 A, B$ ). This lack of effect was evident despite prolonged solution superfusion times (up to
$30 \mathrm{~min}$ ) and was similarly observed with $0 \mathrm{Ca}^{2+}$ and $6 \mathrm{mM} \mathrm{Mg}^{2+}$ solutions. Quantification of the effect of $\mathrm{Ca}^{2+}$ channel blockade on distal dendritic AP repolarization showed a $-1.3 \pm 5.5 \%(n=$ 9) slowing of action potential repolarization (i.e., a small increase in repolarization rate that was not significantly different from 0 ). Comparison of the effects of $\mathrm{Ca}^{2+}$ channel blockade on AP repolarization at the soma and distal dendrites (Fig. $2 C$ ) showed this effect was significantly different between the two groups $(p<$ $0.0005)$. This result shows that for the distal dendrites, $\mathrm{Ca}^{2+}$ activated conductances do not contribute to action potential repolarization as they do at the soma. In dendritic recordings obtained in the proximal dendrites at distances $<150 \mu \mathrm{m}$ from the soma, $\mathrm{Ca}^{2+}$ channel blockade had an effect on AP repolarization that was intermediate between that at the soma and in the distal dendrites. The results obtained in the proximal dendrites are further discussed below.

\section{Blockade of $\mathrm{Ca}^{2+}$-activated $\mathrm{K}^{+}$channels does not affect repolarization of dendritic action potentials}

To determine whether $I_{C}$ contributes to AP repolarization in the dendrites, we applied blockers of this current and elicited backpropagating APs. As shown in Figure $3 A$, bath application of CTX (30 nM), a potent blocker of BK channels at nanomolar concentrations (Miller et al., 1985), caused significant broadening of the somatic action potential. This effect was fairly rapid in onset (4-5 min after initiation of perfusion) but had a slow and incomplete reversal after washing in control saline (data not shown). Application of CTX caused a $37.1 \pm 3.7 \%(n=3)$ decrease in the repolarization slope of somatic APs, similar in magnitude to the slowing caused by $\mathrm{Ca}^{2+}$ channel blockade. The 
A soma control
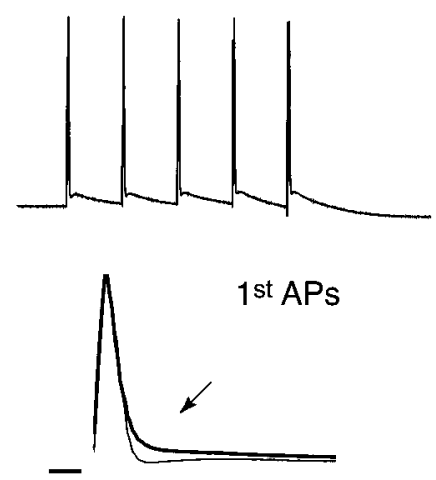

B $120 \mu \mathrm{m}$ dendrite

control

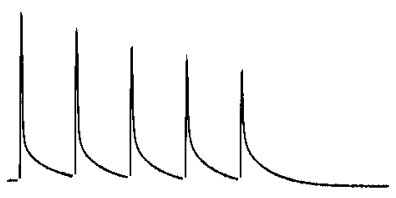

1 st APs

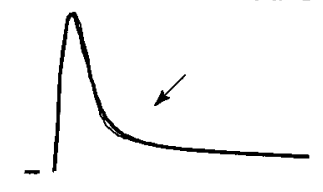

$200 \mu \mathrm{M} \mathrm{Cd}^{2+}$

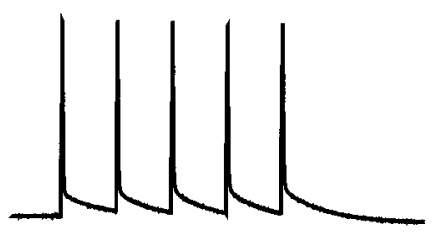

$5^{\text {th }}$ APs



$200 \mu \mathrm{M} \mathrm{Cd}^{2+}$



$5^{\text {th }}$ APs

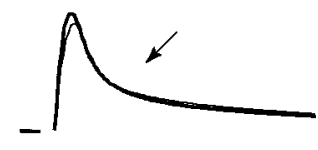

Figure 4. Repetitive firing does not cause activation of dendritic $I_{C}$. A, Top, Short trains of antidromic action potentials were elicited in control and $\mathrm{Cd}^{2+}$ solutions. Bottom, Comparison of superimposed APs in control and $\mathrm{Cd}^{2+}$ solutions from the beginning (left) and end (right) of the train shows that $\mathrm{Ca}^{2+}$ channel blockade had a similar effect on AP repolarization (arrow) at the beginning and end of the train. This suggests that $I_{C}$ activation was nearly maximal with the first AP. $B$, A similar comparison of dendritic APs shows that $I_{C}$ was minimally activated at both the beginning (bottom left) and end (bottom right) of the train of APs.
AP broadening that occurred in CTX differed from that with $\mathrm{Ca}^{2+}$ channel blockers in that CTX caused broadening that began at an earlier point on the repolarizing waveform. This difference may stem either from the possible presence of other voltage-gated non- $\mathrm{Ca}^{2+}$-dependent $\mathrm{K}^{+}$channels that are sensitive to CTX [such as Kv1.3 (Kaczorowski et al., 1996)] or from the contribution of inward $\mathrm{Ca}^{2+}$ currents to the AP waveform, which would be blocked by $\mathrm{Cd}^{2+}$ but unaffected by CTX.

In contrast, application of CTX caused no significant change in the AP waveform recorded in the dendrites (Fig. $3 A$ ), despite perfusion times up to $25-30 \mathrm{~min}$. CTX caused a $1.36 \pm 10.1 \%$ $(n=3)$ decrease in repolarization rate, which was significantly different from the repolarization slowing at the soma caused by CTX $(p<0.01)$. This result, obtained with a high-affinity blocker of $I_{C}$, is a specific demonstration that $I_{C}$ makes little contribution to the repolarization of dendritic action potentials. Similar effects were obtained with perfusion of TEA at concentrations (0.5-1 $\mathrm{mm}$ ) that primarily affect $I_{C}$ (Storm, 1987; Rudy, 1988). As shown in Figure $3 B$, TEA caused somatic AP broadening $(29.4 \pm 4.7 \%$; $n=3$ ) that was similar in appearance to that of CTX. No significant effect was seen when TEA was applied during dendritic recordings $(0.22 \pm 4.4 \% ; n=4 ; p<.005)$, further demonstrating that $I_{C}$ makes little or no contribution to AP repolarization in the distal dendrites.

\section{Repetitive firing does not cause activation of dendritic $I_{C}$}

Because it was apparent that single back-propagating dendritic APs did not cause activation of $I_{C}$, we questioned whether this might be a result of insufficient $\mathrm{Ca}^{2+}$ influx during a single dendritic AP. Previous work using imaging of intracellular $\mathrm{Ca}^{2+}$ concentration $\left(\left[\mathrm{Ca}^{2+}\right]_{i}\right)$ had demonstrated that repetitive firing of back-propagating APs led to increases in $\left[\mathrm{Ca}^{2+}\right]_{i}$ in CA1 pyramidal neuron dendrites that progressively increased with the number of APs for brief trains of stimuli (Jaffe et al., 1992; Callaway and Ross, 1995). Thus, we investigated whether repetitive firing of back-propagating APs could lead to activation of dendritic $I_{C}$.

Trains of five back-propagating APs were elicited by antidromic stimulation at $20 \mathrm{~Hz}$ under control and $\mathrm{Ca}^{2+}$ channel blockade conditions (Fig. 4). Somewhat surprisingly, there was little change in the somatic AP broadening by $\mathrm{Ca}^{2+}$ channel blockers when compared at the beginning and end of the train. In the example shown in Figure $4 A$, application of $200 \mu \mathrm{M} \mathrm{Cd}{ }^{2+}$ caused a fairly constant slowing of repolarization for all APs in the train, with a $39.9 \%$ slowing of the first AP and a $41.1 \%$ slowing of the last AP in the train. This suggests that activation of $I_{C}$ at the soma is nearly maximal with a single action potential.

When the effect of $\mathrm{Ca}^{2+}$ channel blockade was studied during repetitive firing of dendritic APs, it was found that $\mathrm{Ca}^{2+}$ channel blockers continued to have no effect on AP repolarization despite repetitive firing. As shown in Figure $4 B$, comparison of APs elicited at the beginning and end of a $20 \mathrm{~Hz}$ train of stimuli shows that $\mathrm{Ca}^{2+}$ channel blockade has little or no effect on AP repolarization throughout the train. Thus, despite presumably rising levels of dendritic $\left[\mathrm{Ca}^{2+}\right]_{\mathrm{i}}$ during repetitive firing, there is no evidence of dendritic $I_{C}$ activation by back-propagating action potentials. 
A soma



Figure 5. Activation of $I_{C}$ diminishes in the proximal dendrites. $A$, Action potentials recorded at the soma showed a marked slowing of repolarization in $200 \mu \mathrm{M} \mathrm{Cd}^{2+}$ (arrow). $B-D$, Action potentials recorded in the proximal dendrites at progressively greater distances from the soma showed a gradual decrease in the activation of $I_{C}$ (arrows).


\section{Activation of $I_{C}$ diminishes in the proximal dendrites}

One factor that could underlie the absence of $I_{C}$ activation by action potentials in the distal dendrites might be the diminished amplitude of back-propagating APs with increasing dendritic distance. Because the activation of $I_{C}$ is both voltage- and $\mathrm{Ca}^{2+}$ dependent, decreased peak AP amplitude would decrease $I_{C}$ activation both because of the decreased peak depolarization and because of decreased $\mathrm{Ca}^{2+}$ influx through intrinsic voltage-gated $\mathrm{Ca}^{2+}$ conductances. To investigate this possibility, we studied the relation of $I_{C}$ activation and AP amplitude in the proximal dendrites where AP amplitude starts to decline from its value at the soma.

Dendritic recordings were obtained in the proximal dendrites at distances between 25 and $150 \mu \mathrm{m}$, and the effect of $\mathrm{Ca}^{2+}$

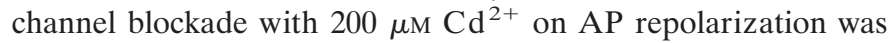
measured. Recordings from several distances are shown in Figure 5. Comparing the effects at the soma and at increasing distances in the proximal dendrites, it appears that the effect of $\mathrm{Cd}^{2+}$ on AP repolarization is maximal at the soma and then progressively declines with distance in the proximal dendrites. A plot of the decrease in AP repolarization slope in $\mathrm{Cd}^{2+}$ versus dendritic distance (Fig. $6 \mathrm{~A}$ ) shows that the effect of $\mathrm{Ca}^{2+}$ channel blockade decreases continuously with distance, with the decrease in repolarization equaling one-half of the somatic value at a distance of $\sim 70 \mu \mathrm{m}$ from the soma.

When the amplitude of the back-propagating AP was normalized to its value at the soma and plotted versus dendritic distance (Fig. 6B), it can be seen that AP amplitude in the dendrites remains similar to its value in the soma $(\sim 100 \mathrm{mV})$ for the first $\sim 70 \mu \mathrm{m}$ of the proximal dendrites and then begins to decline such that at $175 \mu \mathrm{m}$, AP amplitude is $\sim 0.6$ of its value at the soma (or $\sim 60 \mathrm{mV}$ ). Comparison of the normalized decrease in AP repolarization with AP amplitude shows that in the first $70 \mu \mathrm{m}$ of the proximal dendrites, the AP repolarization change progressively diminished while AP amplitude remained nearly constant. For example, at $70 \mu \mathrm{m}$, AP amplitude is similar to the somatic value, whereas the change in repolarization is approximately one-half its value at the soma. Thus, the decrease in $I_{C}$ activation in the dendrites appears unrelated to AP amplitude. It is likely that other factors account for the decline of dendritic $I_{C}$ activation, such as a decreased density of $\mathrm{Ca}^{2+}$-activated $\mathrm{K}^{+}$channels in the dendrites or a similar decrease in the density of dendritic voltagegated $\mathrm{Ca}^{2+}$ channels activated by back-propagating APs.

\section{DISCUSSION}

In this study we have investigated action potential repolarization in the distal dendrites of CA1 hippocampal pyramidal neurons and have found that, unlike APs at the soma, dendritic APs fail to activate large-conductance $\mathrm{Ca}^{2+}$-activated $\mathrm{K}^{+}$current. This lack of $I_{C}$ activation in the distal dendrites was demonstrated by the failure of both $\mathrm{Ca}^{2+}$ channel blockade and $I_{C}$ blockers to affect AP repolarization in the distal dendrites at concentrations that completely blocked $I_{C}$ at the soma. Repetitive firing of APs likewise failed to activate dendritic $I_{C}$. Investigation of AP repolarization in the proximal dendrites showed that $I_{C}$ activation by single APs progressively diminished within the proximal dendrites and disappeared at a distance of $100-150 \mu \mathrm{m}$ from the soma. Thus, the activation of $I_{C}$ by action potentials appears to be 
A

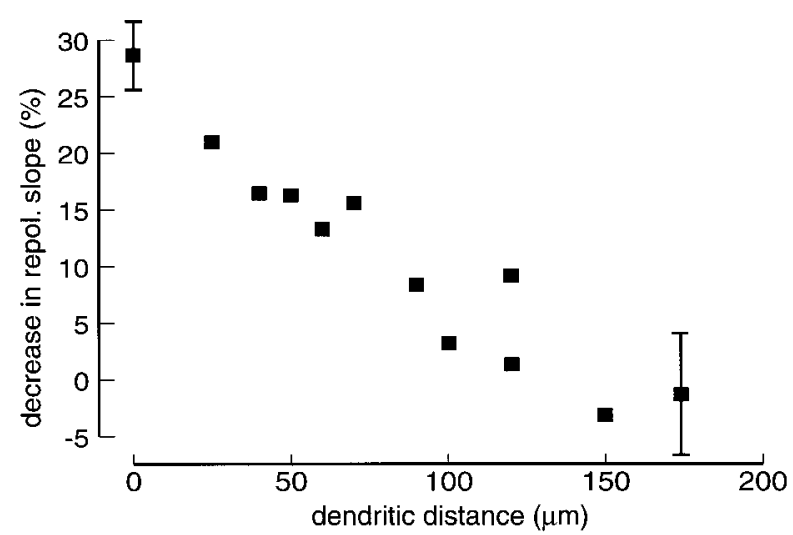

B

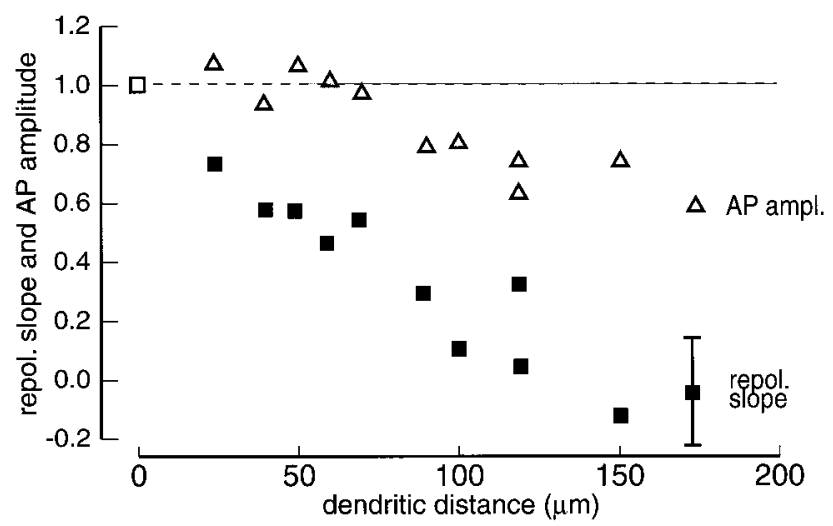

Figure 6. The decrease in dendritic $I_{C}$ activation does not depend on action potential amplitude. $A$, A plot of the decrease in action potential repolarization rate with $\mathrm{Ca}^{2+}$ channel blockade versus distance in the dendrites from the soma. In this case, the repolarization rate at both the soma and dendrites was computed as the slope of AP repolarization measured between 80 and $30 \%$ of action potential amplitude. Each point represents a single experiment, with the values at the soma (dendritic distance $=0$ ) and at $174 \mu \mathrm{m}$ (mean distal dendritic recording location) representing the mean values of experiments at that location $(n=8$ at the soma; $n=9$ in the distal dendrites). Note that $I_{C}$ activation decreased continuously from its value at the soma with increasing dendritic distance. $B$, The decrease in repolarization slope (squares) and AP amplitude (triangles) normalized to these values at the soma and plotted versus dendritic distance. [The SEM of the mean AP amplitude (ampl.) in the distal dendrites was less than the symbol size.] In the proximal dendrites up to $\sim 70 \mu \mathrm{m}$, AP amplitude was nearly invariant, whereas the activation of $I_{C}$ declined. Thus, the diminishing activation of $I_{C}$ in the dendrites was not a function of decreasing AP amplitude.

nonuniform within the CA1 pyramidal neuron, diminishing with distance in the apical dendrites. Because this current is responsible in part for the rapid repolarization of the somatic AP and the fast AHP that follows the AP, its lack of activation in the distal dendrites results in dendritic action potentials that repolarize significantly more slowly than somatic APs and show no fast AHP.

Because $I_{C}$ activation is both voltage- and $\mathrm{Ca}^{2+}$-dependent, the progressive loss of $I_{C}$ activation with distance in the dendrites could have several explanations: decreasing AP amplitude, diminished $\mathrm{Ca}^{2+}$ influx triggered by back-propagating APs, or a lack of $I_{C}$ itself in the dendrites. Dendritic AP amplitude decrements with distance from the soma and could affect $I_{C}$ activation both by decreased membrane depolarization and by decreased $\mathrm{Ca}^{2+}$ influx through intrinsic $\mathrm{Ca}^{2+}$ conductances driven by the depolarization. This is unlikely to explain the results for two reasons.
First, $I_{C}$ activation began to decline in the proximal dendrites where AP amplitude was equal to that of the soma $(\sim 100 \mathrm{mV})$; for example, at $70 \mu \mathrm{m}$ from the soma, AP amplitude is still $\sim 100$ $\mathrm{mV}$, but $I_{C}$ activation had declined to approximately one-half the somatic value. Second, $\mathrm{Ca}^{2+}$-imaging experiments have shown that increases in $\left[\mathrm{Ca}^{2+}\right]_{\mathrm{i}}$ induced by back-propagating APs are actually larger in the proximal dendrites than in the soma (reaching a peak at $\sim 100 \mu \mathrm{m}$ from the soma) and thus would have been expected to cause maximal activation of $I_{C}$ (Jaffe et al., 1992; Callaway and Ross, 1995).

It is possible that $I_{C}$ activation depends on $\mathrm{Ca}^{2+}$ influx through a specific $\mathrm{Ca}^{2+}$ channel subtype that is nonuniformly distributed throughout the pyramidal neuron. Marrion and Tavalin (1998) have reported that BK channels in excised membrane patches from hippocampal pyramidal neuron somata are selectively activated by $\mathrm{N}$-type $\mathrm{Ca}^{2+}$ channels and not by $\mathrm{L}$ - or $\mathrm{P} / \mathrm{Q}$-type channels. N-type channels have been found in significant density at the soma but occur at a much lower density in CA1 pyramidal neuron dendrites (Magee and Johnston, 1995a); thus, it is possible that insufficient $\mathrm{Ca}^{2+}$ influx is mediated by these channels to activate dendritic $I_{C}$. This assumes that BK channels in the dendrites have the same predilection for $\mathrm{Ca}^{2+}$ influx through N-type $\mathrm{Ca}^{2+}$ channels as do somatic channels and cannot be activated by $\mathrm{Ca}^{2+}$ influx through other channel subtypes.

An additional possible explanation for the lack of activation of dendritic $I_{C}$ depends on the distribution of the underlying conductance itself. The most straightforward hypothesis is that $\mathrm{BK}$ channels are primarily confined to the soma or to the soma and proximal dendrites. This would be in agreement with the findings of Knaus et al. (1996) who described the distribution of slo (the BK channel gene) mRNA and protein in the hippocampus as confined primarily to the pyramidal cell layer and to mossy and perforant path fibers. Furthermore, slo has been found to undergo alternative splicing to yield numerous isoforms with wide variation in their $\mathrm{Ca}^{2+}$ sensitivity (Tseng-Crank et al., 1994), so dendritic $\mathrm{BK}$ channels might exist as isoforms that are markedly less sensitive to $\mathrm{Ca}^{2+}$ than is their somatic counterpart and thus are not activated by dendritic APs.

Other than the present study, there are little previous data that describe the activation of $I_{C}$ in dendrites. One study using blind intradendritic recordings of presumed pyramidal dendrites found that AP repolarization was sensitive to prolonged application of $\mathrm{Co}^{2+}$ in some recordings, although it was not reported at what dendritic distance this observation occurred (Andreasen and Lambert, 1995). Sah and Bekkers (1996) examined decay time constants of IPSCs to infer that slow AHP currents mediated by SK channels were distributed on the proximal dendrites, but this study did not investigate the currents underlying the fast AHP. Previous cell-attached recordings in CA1 pyramidal neuron dendrites have noted the infrequent appearance of BK-like channel openings, usually under circumstances of poor cell health (D. Hoffman, personal communication). This last finding would support the presence of BK channels in dendrites, although at an unknown density and of unknown biophysical properties.

The lack of dendritic $I_{C}$ activation has a significant effect on the shape of the back-propagating dendritic action potential, causing it to repolarize more slowly. This change in AP shape likely affects dendritic integrative properties. For example, slower dendritic AP repolarization will cause greater inactivation of both dendritic $\mathrm{Na}^{+}$and A-type $\mathrm{K}^{+}$currents, which may limit the ability of the dendrites to follow fast repetitive firing at the soma. Broad dendritic APs will also have an increased unblocking effect 
on the voltage-dependent conductance of NMDA receptors, which can lead to increased $\mathrm{Ca}^{2+}$ influx during paired backpropagating APs and synaptic stimuli (Magee and Johnston, 1997; Koester and Sakmann, 1998; Schiller et al., 1998). Furthermore, the lack of $I_{C}$ may explain in part the lowered dendritic threshold for $\mathrm{Ca}^{2+}$ spiking, because these regenerative responses are mediated by high-threshold $\mathrm{Ca}^{2+}$ channels that are usually activated on the repolarizing phase of preceding dendritic $\mathrm{Na}^{+}$ APs (Andreasen and Lambert, 1995; Magee and Johnston, 1995b). Conversely, the localization of BK channels predominantly to the soma and axon terminals, as shown by anatomic data (Knaus et al., 1996), suggests that $I_{C}$ is most important for regulating the shape of orthodromically propagating action potentials, especially at the axon terminal, where AP width can have significant effects on neurotransmitter release.

Although the relative lack of $I_{C}$ activation significantly affects dendritic AP shape, it is clearly not the only factor. Dendritic AP back-propagation is also affected by the progressive increase in A-current with dendritic distance, which decreases AP amplitude and raises the threshold for dendritic AP initiation (Hoffman et al., 1997). Under conditions of $I_{C}$ blockade or both $I_{C}$ and A-current blockade (Hoffman et al., 1997), dendritic APs still repolarize significantly more slowly in the dendrites than in the soma. This would suggest a relative lack of some other conductance, most likely a rapidly activating delayed rectifier; one possibility would be $\mathrm{K}^{+}$channels containing the $\alpha$ subunit encoded by Kv2.1, which have been found to be a significant component of the delayed-rectifier $\mathrm{K}^{+}$current in hippocampal neurons and appear to be confined to the soma and proximal dendrites $(\mathrm{Mu}-$ rakoshi and Trimmer, 1999). This possibility, along with the present finding of a relative lack of dendritic $I_{C}$ activation, joins accumulating evidence that voltage-gated ion channels are distributed nonuniformly within the hippocampal pyramidal neuron and that this regional nonuniformity shapes the signal-processing capabilities of the neuron.

\section{REFERENCES}

Andreasen M, Lambert JDC (1995) Regenerative properties of pyramidal cell dendrites in area CA1 of the rat hippocampus. J Physiol (Lond) 483:421-441.

Barrett JN, Magleby KL, Pallotta BS (1982) Properties of single calcium-activated potassium channels in cultured rat muscle. J Physiol (Lond) 331:211-230.

Blatz AL, Magleby KL (1984) Ion conductance and selectivity of single calcium-activated potassium channels in cultured rat muscle. J Gen Physiol 84:1-23.

Callaway JC, Ross WN (1995) Frequency-dependent propagation of sodium action potentials in dendrites of hippocampal CA1 pyramidal neurons. J Neurophysiol 74:1395-1403.

Colbert CM, Johnston D (1996) Axonal action-potential initiation and $\mathrm{Na}^{+}$channel densities in the soma and axon initial segment of subicular pyramidal neurons. J Neurosci 16:6676-6686.

Colbert CM, Magee JC, Hoffman DA, Johnston D (1997) Slow recovery from inactivation of $\mathrm{Na}^{+}$channels underlies the activity-dependent attenuation of dendritic action potentials in hippocampal CA1 pyramidal neurons. J Neurosci 17:6512-6521.

Elliott EM, Malouf AT, Caterall WA (1995) Role of calcium channel subtypes in calcium transients in hippocampal CA3 neurons. J Neurosci 15:6433-6444.

Hoffman D, Magee JC, Colbert CM, Johnston D (1997) $\mathrm{K}^{+}$channel regulation of signal propagation in dendrites of hippocampal pyramidal neurons. Nature 387:869-875.

Jaffe DB, Johnston D, Lasser-Ross N, Lisman JE, Miyakawa H, Ross WN (1992) The spread of $\mathrm{Na}^{+}$spikes determines the pattern of dendritic $\mathrm{Ca}^{2+}$ entry into hippocampal neurons. Nature 357:244-246.

Kaczorowski GJ, Knaus H-G, Leonard RJ, McManus OB, Garcia ML (1996) High-conductance calcium-activated potassium channels; structure, pharmacology, and function. J Bioenerg Biomembr 28:255-267.

Knaus H-G, Schwarzer C, Koch RO, Eberhart A, Kaczorowski GJ, Glossmann H, Wunder F, Pongs O, Garcia ML, Sperk G (1996) Distribution of high-conductance $\mathrm{Ca}^{2+}$-activated $\mathrm{K}^{+}$channels in rat brain: targeting to axons and nerve terminals. J Neurosci 16:955-963.

Koester HJ, Sakmann B (1998) Calcium dynamics in single spines during coincident pre- and postsynaptic activity depend on the relative timing of back-propagating action potentials and subthreshold excitatory postsynaptic potentials. Proc Natl Acad Sci USA 95:9596-9601.

Lancaster B, Adams PR (1986) Calcium-dependent current generating the after hyperpolarization of hippocampal neurons. J Neurophysiol $55: 1268-1282$.

Lancaster B, Zucker RS (1994) Photolytic manipulation of $\mathrm{Ca}^{2+}$ and the time course of slow, $\mathrm{Ca}^{2+}$-activated $\mathrm{K}^{+}$current in rat hippocampal neurones. J Physiol (Lond) 475:229-239.

Magee JC (1998) Dendritic hyperpolarization-activated currents modify the integrative properties of hippocampal CA1 pyramidal neurons. J Neurosci 18:7613-7624.

Magee JC, Johnston D (1995a) Characterization of single voltage-gated $\mathrm{Na}^{+}$and $\mathrm{Ca}^{2+}$ channels in apical dendrites of rat CA1 pyramidal neurons. J Physiol (Lond) 487:67-90.

Magee JC, Johnston D (1995b) Synaptic activation of voltage-gated channels in the dendrites of hippocampal pyramidal neurons. Science 268:301-304.

Magee JC, Johnston D (1997) A synaptically controlled, associative signal for Hebbian plasticity in hippocampal neurons. Science 275:209-213.

Marrion NV, Tavalin SJ (1998) Selective activation of $\mathrm{Ca}^{2+}$-activated $\mathrm{K}^{+}$channels by co-localized $\mathrm{Ca}^{2+}$ channels in hippocampal neurons. Nature 395:900-905.

Mickus T, Jung H-y, Spruston N (1999) Properties of slow, cumulative sodium channel inactivation in rat hippocampal CA1 pyramidal neurons. Biophys J 76:846-860.

Miller C, Mocydlowski E, Latorre R, Phillips M (1985) Charybdotoxin, a protein inhibitor of single $\mathrm{Ca}^{2+}$-activated $\mathrm{K}^{+}$channels from mammalian skeletal muscle. Nature 313:316-318.

Murakoshi H, Trimmer JS (1999) Identification of the Kv2.1 K ${ }^{+}$channel as a major component of the delayed rectifier $\mathrm{K}^{+}$current in rat hippocampal neurons. J Neurosci 19:1728-1735.

Rudy B (1988) Diversity and ubiquity of K channels. Neuroscience 25:729-749.

Sah P (1996) $\mathrm{Ca}^{2+}$-activated $\mathrm{K}^{+}$currents in neurones: types, physiological roles and modulation. Trends Neurosci 19:150-154.

Sah P, Bekkers JM (1996) Apical dendritic location of slow afterhyperpolarization current in hippocampal pyramidal neurons: implications for the integration of long-term potentiation. J Neurosci 16:4537-4542.

Schiller J, Schiller Y, Clapham DE (1998) NMDA receptors amplify calcium influx into dendritic spines during associative pre- and postsynaptic activation. Nat Neurosci 1:114-118.

Spruston N, Schiller Y, Stuart G, Sakmann B (1995) Activity-dependent action potential invasion and calcium influx into hippocampal CA1 dendrites. Science 268:297-300.

Storm JF (1987) Action potential repolarization and a fast afterhyperpolarization in rat hippocampal pyramidal cells. J Physiol (Lond) 385:733-759.

Tseng-Crank J, Foster CD, Krause JD, Mertz R, Godinot N, DiChiara TJ, Reinhart PH (1994) Cloning, expression, and distribution of functionally distinct $\mathrm{Ca}^{2+}$-activated $\mathrm{K}^{+}$channel isoforms from human brain. Neuron 13:1315-1330.

Vergara C, Latorre R, Marrion NV, Adelman JP (1998) Calciumactivated potassium channels. Curr Opin Neurobiol 8:321-329. 